Article

\title{
Collaboration between doctoral researchers and patient research partners: reflections and considerations
}

\author{
Bethan Jones ${ }^{1, *}\left(\mathbb{D}\right.$, Andrew Hunt ${ }^{2}$ \\ 'School of Healthcare Sciences, Cardiff University, UK \\ 2Patient Research Partner, Rheumatology Department, Bristol Royal Infirmary, UK \\ *Correspondence: jonesb94@cardiff.ac.uk
}

Submission date: 24 November 2020; Acceptance date: 7 July 2021; Publication date: 20 January 2022

\section{How to cite}

Jones, B. and Hunt, A. (2022) 'Collaboration between doctoral researchers and patient research partners: reflections and considerations'. Research for All, 6 (1), 2, 1-9. DOI: https://doi.org/10.14324/RFA.06.1.02.

\section{Peer review}

This article has been peer-reviewed through the journal's standard double-blind peer review, where both the reviewers and authors are anonymised during review.

\section{Copyright}

2022, Bethan Jones and Andrew Hunt. This is an open-access article distributed under the terms of the Creative Commons Attribution Licence (CC BY) 4.0 https://creativecommons.org/licenses/by/4.0/, which permits unrestricted use, distribution and reproduction in any medium, provided the original authors and source are credited • DOI: https://doi.org/10.14324/RFA.06.1.02.

\section{Open access}

Research for All is a peer-reviewed open-access journal.

\begin{abstract}
A key principle of working in collaboration with patient research partners (patients contributing to research projects as team members, rather than as participants) is that they should be equal partners with researchers and health professionals. This presents a challenge in doctoral research, where students are expected to own their research decisions. Consequently, efforts are required to ensure that patient partners' involvements are not tokenistic. This case study brings together the reflections of a recently completed doctoral student and a patient partner, who was part of the doctoral supervisory team. It discusses the role that the patient partner took during the doctorate and the activities in which he was involved. Both the researcher and the patient partner reflect on their expectations and experiences of collaboration. These reflections include factors that facilitated good working practices, the process of building rapport, and the benefits each got out of their collaboration. The interactions exploring 'the dance of academia' (the processes that were formally part of the PhD process or the aspects of academic work that were not directly related to completing the research) required recognition. Open, ongoing communication and practical considerations to support the patient partner were key to establishing a strong working relationship, and to determining what a meaningful contribution looked like at each stage of the
\end{abstract}


process. Working with a patient partner as a doctoral student adds value to the doctoral process, and it is a vital opportunity to develop good practice as a researcher.

Keywords collaboration; patient and public engagement; impact; reflection; doctoral research

\section{Key messages}

- This collaboration between doctoral student and patient partner has added credibility, applicability and usefulness for the doctoral student, and feelings of valued contribution and positivity for the patient research partner.

- It is possible to find a balance between the doctoral student maintaining project ownership and including meaningful patient partner collaboration.

- It is important to support doctoral students to work meaningfully alongside patient research partners, including providing appropriate training. This has the potential to develop future researchers with the appropriate skills and values to build strong collaborations with patients and the public.

\section{Background}

Over time, patient and public involvement (PPI) in co-creating and contributing to health services development, research and innovation has substantially increased to become expected good practice (Holmes et al., 2019). There is also mounting evidence that increased PPI could improve research usefulness and reduce power imbalances that often leave patients' voices unheard (Ocloo and Matthews, 2016). Increased PPI can also add significant practical value to studies, as those with patient partner involvement are more likely to recruit to target, retain participants and identify meaningful results (Ennis and Wykes, 2013).

Working alongside patients in health research can entail a range of activities, durations and purposes depending on the project aims, patient strengths and interests, and other engagement ongoing with the community. However, a key principle of PPI is active dialogue where professionals and patients are equal partners (Janamian et al., 2016). It is also vital to consider and tackle potential barriers and challenges to PPI, particularly when these disproportionately impact a patient partner, such as transportation costs, time and well-being.

Research doctorates such as PhDs are typically conducted over several years, and are a form of research apprenticeship. Universities and postgraduate schools require students to take ownership over the direction and design of their research. Students are supported by a supervisor or team of supervisors selected for the specific skills they bring to the project, such as methodology or subject expertise. A patient partner brings equally important expertise in their experience of living with the condition being studied. While it is important that the doctoral student retains ownership of the project in comparison to the other members of the supervisory team, these boundaries are often different with professional supervisors, who see the research in a broad professional context, compared to patient partners, who share personal experience.

Tokenism is a factor that should be addressed from the outset to allow the relationship between researcher and patient partner to develop along productive and collaborative lines. Tokenism can occur when professionals include patient partners, but the patient partners have very little opportunity to influence the process meaningfully. This can contribute to superficial and surface-level patient involvement, which gives the appearance of collaboration, but does not share power and influence with patient partners. Finding a suitable balance between avoiding tokenistic PPI and ownership of the doctoral project is particularly challenging. Other case studies have reported the experience of incorporating PPI 
into doctoral research, but the extent of the PPI and the students' experiences have varied (Coupe and Mathieson, 2019; Tomlinson et al., 2019; Dawson et al., 2020). It is clear that PPI in doctoral research does not have a single 'one size fits all' model, and additional case studies consider other ways in which patient partners can contribute to doctoral research.

This paper presents a worked example of PPI during doctoral research from the perspectives of a doctoral student and a patient research partner. It discusses the experiences and reflections that have led to learning and mutual benefits for both the doctoral student and the patient research partner. This piece is co-written, so that both authors can reflect on their perspectives.

\section{Context}

The project was part of a PhD focused on self-management and patient activation (how able and willing someone is to take an active role in managing their health) (Jones, 2020). Beth was part of the Rheumatology Research Team and located in the Bristol Royal Infirmary, where the rheumatology team have a long history of collaborating with patients in clinical and research contexts (Hewlett et al., 2006). PPI within academic rheumatology also has a strong documented history, particularly around developing outcome measures and the greater focus on fatigue in both research and clinical care (Goel, 2020; De Wit and Adebajo, 2019).

In Beth's department, there is typically at least one patient partner on each project to provide the patient perspective and to contribute to the design and running of research. These patient partners are often recruited through discussion with health-care professionals in clinics, although efforts are in progress to recruit patient partners through other avenues. The team try to ensure that the patient partner and project are good fits for each other in terms of health experiences (for example, ensuring that a patient partner is recruited that has a specific health condition) and experiences relevant to the study (for example, patient partners on a study developing a fatigue intervention will have experienced fatigue as one of their symptoms). Patient partners are also matched according to the amount of time they would like to commit, and the interest they have in the topic and methods. The team provide a range of engagement opportunities for patient partners at a range of levels of involvement. This allows patient partners to be able to commit to an opportunity and project that best suits them.

For this project, Andrew was the sole patient partner, and he was attached to the project before Beth was appointed as the student. He was recruited for this project in particular because of his experience of actively self-managing a rheumatic condition. This $\mathrm{PhD}$ project had a supervisory team of four members, including Andrew. The other members were:

- an associate professor in rheumatology and self-management with expertise in mixed-methods selfmanagement in rheumatology, who acted as director of studies (lead PhD supervisor)

- a professor of rheumatology nursing with expertise in the clinical care of inflammatory arthritis and research incorporating patients' perspectives in rheumatology

- a professor of appearance and health psychology with expertise and interests in interventions that focus on the psychosocial impact of long-term conditions.

The project began in November 2016 and Beth submitted her PhD thesis in late 2019.

\section{Expectations}

Beth began her PhD with some experience of working collaboratively with patients clinically, but she had not worked with a patient partner in research before. She was hoping for a patient partner who was willing to participate in all aspects of the research, including reviewing the thesis and disseminations to help it reflect the patient voice. Given that the thesis topic was very focused on patient experience, it would not have been appropriate to progress without multiple sources of patient involvement. Consequently, 
a patient partner involved for the duration of the project was one of the strands of PPI (among other engagement with patient groups). In some ways, there was a shared experience between Beth and Andrew of learning about patient partner involvement in research together, as this was the first substantial and long-term experience of collaborating in this way in research for both parties. This offered an opportunity to learn together. This collaboration met Beth's expectations and hopes for a patient partner working relationship, and Andrew was very involved in the process.

Andrew came from a teaching background, and he took up his role as a patient partner following a change in health as a way of using his skills to support the learning process. This was balanced by a personal desire to see his medical condition in a more positive light. He was enthusiastic to reflect on, and share, his experience as a patient. This was his first experience of being a patient partner, and of working in a patient partner PhD supervisor capacity.

Andrew was also keen that his involvement avoided tokenism, in that he wanted to be more than 'a box ticked'. He wanted to play a supportive role and respond to the development of the research and researcher, rather than bringing any preconceived agenda to the project. His expectations were met in the supportive role he played in the project. Andrew played many roles throughout, but he particularly saw himself as a 'critical friend' patient partner (Barker et al., 2020). Other members of Beth's supervisory team played different roles in their capacity on the team, due to their supervisory, pastoral and academic responsibilities. They brought specific responsibilities and academic expertise, and all had experience of supervising multiple doctoral students to the completion of their degree. Andrew's role did not have any set expectations in terms of his collaboration style, and consequently he made use of the critical friend role above others.

A crucial part of Andrew's approach was recognising that his voice did not reflect or represent all rheumatology patients everywhere, and that he was just reflecting his own experience, rather than being a representative of 'the patient voice' in general, because others may have different perspectives and opinions. As the use of a single patient partner has been criticised previously, and they cannot and should not speak for all patients (Gilbert, 2019), Andrew looked to develop a wider understanding of patient perspectives, and he discussed aspects of the broad topic with some of his fellow patients at his local patient group. This contributed to an additional layer of PPI that Andrew used when reflecting on aspects of the project to mitigate the limitations of a single patient partner. While we both acknowledge the risk of having just one patient partner attached to the project, we worked to reduce this, with ongoing discussions with this patient group and member checking of analysis built into one of the studies in the project.

\section{Navigating 'the dance' of academic research: finding balance and ownership}

Andrew's involvement in the project spanned formal PhD-related events and more informal, ongoing contact about the project. He attended all supervisory team meetings to participate in discussion, contribute questions around the design of studies, or review the overall findings and implications of data collection. He reviewed documents such as protocols, ethics applications, and conference abstracts or other dissemination opportunities. Andrew contributed to piloting qualitative interviews and a quantitative survey to provide feedback prior to data collection. This feedback went beyond commenting on practicalities and presentation of the data collection, to discussing the topics covered and outcomes targeted. He also reviewed all outputs of the $\mathrm{PhD}$, including the thesis itself, and he participated in a mock viva (a practice version of a final examination for a PhD, where the student discusses and defends their work).

Beth and Andrew also regularly exchanged emails sharing literature. This initially began with Beth sending plain language summaries of aspects of the field and key debates and issues for Andrew to understand the context around the project. This process was also beneficial for Beth in her experience of 
getting to know the research field and being able to identify and synthesise key literature in accessible summaries. This progressed, at Andrew's request, to the sharing of journal articles relevant to the project. Finally, this became a two-way process, and Andrew sent reading he had come across to Beth for consideration. Both should acknowledge that Andrew's abilities, skills and engagement facilitated easier collaboration. Andrew had the ability to read academic papers and understand much of the terminology, and he was confident enough to ask questions when there were things he did not know or understand. This meant he was comfortable engaging in the research process. Other patient partners may require more training or more adaptation to ensure that they are comfortable collaborating if they do not have these skills. Lacking these skills might also be a barrier to people feeling able to become patient partners. Andrew's personal experience of teaching professionally, as well as conducting research of his own during further professional study, also facilitated his ability and readiness to become an active and engaged partner in the process.

Because of the nature of doctoral research, the case study presented here is one where the partnership cannot be equal. As a doctoral researcher, being able to own and defend the decisions taken throughout the research is vital. Therefore, Andrew took on more of a 'patient supervisor' role, and he acted as a patient partner and one of the supervisory team. He contributed to the direction and focus of the work in the same way as other members of the supervisory team. While Beth made the decisions, Andrew played a vital role in the steering of the project.

Andrew has since come to reflect on his belief that his role was to serve the research and Beth's PhD completion. He believes that the success of the partnership required dedication and time commitment from Beth to incorporate PPI into her working practice. It remains his belief that while he had everything to gain, Beth had more to lose had the collaborative relationship become challenging.

This collaboration evolved for both organically as the project progressed, following a meeting at the beginning of the PhD to establish the type of involvement both were hoping for, expectations and working practice preferences. This was informally reviewed regularly, during one-to-one meetings.

This did not mean that both always agreed on all points related to the project. Reviewing the findings of one study saw Beth and Andrew having different interpretations of why a particular subgroup of participants may feel a specific patient questionnaire comprehensively captured their self-management behaviours. This difference in perspective was noted in Andrew's comments on the thesis document initially, and Beth raised it as a discussion point at their next meeting. This allowed a negotiated conversation to discuss both perspectives, and for Beth to consider Andrew's opinion. Ultimately, while his perspective on this was not noted in the PhD thesis for brevity, it has been incorporated into talks when Andrew has co-presented with Beth. This process ensured that Andrew's voice was heard and his perspectives considered, but it also gave Beth the opportunity to determine what did not fit with the flow and word limits of chapters, and to come to a compromise with Andrew.

\section{'The dance of academia'}

Some of the most critical work was done during more informal meetings between Beth and Andrew. These allowed a slower-paced, less decision-oriented opportunity to reflect on facets of the field and project from different perspectives. These meetings were regular, taking place in blocks of two hours approximately every six to eight weeks, and they took place away from hospital or university sites in coffee shops (selected to meet accessibility needs, proximity to easy travel, and coffee/cake quality). These meetings were protected in Beth's diary in recognition of both Andrew's time and the value that the meetings brought to the PhD process. The less formal atmosphere allowed longer discussion about the field of research and the practical implications of the project.

In comparison to this, some of the formalities of the process required navigating what Andrew came to refer to as 'the dance of academia' to contextualise their place in the PhD journey. Activities that Andrew noted as part of 'the dance' included progression reviews, formalities around viva examination 
and research governance procedures, and they could be summarised as anything that did not involve specifically working on the research project. These activities, and the subsequent 'dancing', encompassed aspects of academia and the PhD journey that fell outside the specific scope of the research project according to Andrew. Activities and knowledge that formed part of 'the dance' also included placing the project in the context of wider research and determining the necessary structure of the research to achieve a PhD. We came to conclude that different professions all have their own types of dances in order to work in that field, and that the dance steps are not always clear to those outside the field. Therefore, joining the supervisory team and taking on this role meant that Andrew was learning parts of 'the dance', but he had no desire to perform it himself when it came to adding value to the project.

Andrew contributed to some of these dance-related activities, such as approving on progression reports as a member of the supervisory team and taking part in the mock viva. However, 'is this part of the dance?' became a common question that Andrew asked. This would either be to determine if it was an aspect of the research (such as complex GDPR terminology on information sheets designed to have accessible language), or a practical step of the process about which he felt he did not require the details (such as the process of research permissions including ethics approval), which Andrew deemed to be 'dancing'. This allowed Andrew to determine in which parts of the process he felt he had a role to play. For example, he would read study documents for ethics approvals and discuss aspects of the study design that would ensure it was suitable for patients. However, he did not read the ethics application in its entirety. In doing this, he felt this spared Beth time in explanation, while maintaining meaningful input. However, Andrew was always invited to events, with the opportunity to decline. As the relationship strengthened, he attended and commented on a greater proportion of the dance-related activities (for example, progression reports for Beth's formal graduate school review each year).

Something to note upon reflection is that Andrew has a thoughtfully assertive personality, so he was able to decline activities where he felt his presence was not necessary. Therefore, there is clear value in shaping a research culture where patient partners feel able to be selective about what they attend during projects. Similarly, training doctoral researchers to be sensitive to patient partners' time, and communicating the purpose of meetings and events, clearly can reduce the risk of people feeling obliged to attend everything because they want to be helpful. Not all activities will be a good use of all patient partners' time, and communication with individuals can allow them to identify their priorities and preferences.

\section{Practical considerations}

As this was a longer-term involvement opportunity, Beth incorporated specific practical strategies to ensure Andrew's well-being wherever possible. These were critical, and while they will not be universal for all patient partners, they may be transferable to other circumstances.

\section{Finances}

An important consideration is that Andrew gave his time voluntarily. While INVOLVE guidelines suggest offering payment that is consistent with other team members, and Andrew was offered financial compensation for his time at regular points throughout the project, it was his explicit preference that he did not receive financial compensation for his involvement (NIHR, 2021). He opted for this to best manage his personal financial arrangements. However, Andrew did have travel expenses covered throughout the project.

\section{Time}

Andrew had a clear understanding of the potential time commitment he would have to consider. He also believed that the activities related to the project should be given appropriate time and priority. $\mathrm{He}$ managed his daily schedule to ensure that he had the energy to fulfil his project commitments. 
To respect Andrew's time, Beth ensured that he had plenty of notice for meetings or work requiring review. When work required feedback from the supervisory team, Andrew saw it in advance of it being sent to other supervisors, where possible. This allowed him more time to pace out reviewing and responding. Andrew ensured that time was available for the review process, and that responses were timely for Beth to move forward. As Beth reached the final months of her PhD, and her working hours were longer and less structured, she only contacted Andrew during traditional working hours. Andrew does not have an institutional email address, so Beth avoided interrupting his evenings and weekends. Offering patient partners institutional email addresses, or advising them to create a separate email account for their role (as Andrew did), could allow them to opt in to receiving contact about research when it suits them.

\section{Collaborating with consideration}

Face-to-face contact was arranged to best suit Andrew, with Beth offering several dates and broad time slots. This typically entailed no early mornings, or locations that were challenging to physically access (such as flights of stairs). Ongoing communication with Andrew ensured reduced research activity when Andrew had other commitments, was on holiday or experiencing a flare. Meeting frequency also had seasonal fluctuations to reduce the risk of passing on a cold or winter illness, as both Beth and Andrew are immunosuppressed. This shared experience helped open and ease communication about Andrew's ongoing health, and contributed to the building of this working partnership.

\section{Privacy}

Ensuring Andrew's privacy also required consideration. Beth did not share his email address or copy him into email contact without explicit consent. As Andrew was contributing in a personal capacity, and was not in any organisational directories, his contact information remained private.

Andrew's role included sharing experience of life with his condition. However, Beth worked to ensure that he did not feel coerced to share more than he felt comfortable with. She was thoughtful about asking open questions to ensure that they were not too intrusive, and she regularly reminded Andrew that he could decline to comment on aspects of his experience. This was vital during team meetings to avoid him feeling obliged to share details. Andrew is also a named co-author on anything published related to the project, and he oversees any content related to his role and what he discloses about himself.

\section{Adding value and feeling valued}

Collaborating together brought value in multiple layers. This includes the value of Andrew's involvement in the PhD project, and the additional value this added for the project impact on the wider patient community. We both have individual reflections on this value.

\section{Beth}

Collaborating with Andrew has made me feel that my research is more credible, and more confident that it has potential value for patients. If my ideas or focus move away from something patients can benefit from, then Andrew is willing to give me a gentle nudge to consider the implications of my work. Our ongoing discussions challenge my assumptions and give me a bigger picture to consider. My writing and research materials are more likely to be jargon-free and patient friendly. This is thanks to Andrew's design input and feedback testing them out. Andrew is thoughtful with providing critique when it is needed, and his perspectives have shaped my entire PhD. For example, discussions around how he uses information related to his health opened up my understanding about how vital health literacy (how you find, evaluate and use health-related information) is for self-management. My PhD project was more relevant and practically useful because of Andrew's involvement, and I have found the process of collaborating rewarding and enjoyable. 


\section{Andrew}

Working with Beth has allowed me to find positives in the way my life has changed. Strangely, it also enables me to see my condition in a more optimistic light. It is very easy, when your life changes through ill health, to focus on what you have lost: career, social activities, changes in energy levels, changes in relationships, even a change in the way I approach sunlight! However, given the opportunity to act in a constructive way, and to be a small part of something which is wholly positive, it is possible to change your perspective. I can see 'the now' in a different light, and as something that has definite value. It is not that as an individual I am important, or that what I say is of major significance. It is that my role within the research team and my working relationship with Beth have purpose, and that I am a part of a working group and able to contribute to something that is wholly positive. On a purely personal note, which would not apply to all patient partners, engagement in this level of research allowed me to reconsider the skills and experiences I had gathered through my career in education. This was not just from the teaching perspective, but also as a learner. As a patient partner on a project with breadth and significance to the wider patient community, I really valued the opportunity to consider knowledge and understanding within a totally new setting.

\section{Discussion}

A key element of this positive working relationship is the openness and thoughtfulness on both sides to make it productive without being exploitative. While neither Beth nor Andrew received formal training to prepare for this collaboration, both feel that an induction for early career researchers and patient partners could set a positive tone for others in this situation. This might cover good practice, expectations from both sides, and formalising the preferences and requirements for communication and the patient partner role. Additionally, considering and determining how either researchers or patient partners can access support if there are challenges or communication difficulties (for example, via supervisors or a specific third-party liaison) would add support, should issues arise. This was not the case for this project, and together we wonder if this is due to a good personality fit, above and beyond efforts we made to communicate together well. Beth's PhD journey was also comparatively smooth, with few difficult life events and no need to pause the process, and this may have helped reduce the likelihood of difficulties.

We encountered very few challenges throughout the process, and this is something we explored during the process of drafting this paper. This may in part be due to a willingness to share power, an openended form of collaboration that was flexible to suit Andrew's needs, and his existing skills that made him more confident engaging in this process. We made pre-emptive efforts to avoid other challenges that can contribute to difficulties when working with patient partners, such as inaccessible locations and unclear expectations of time or work, through ongoing discussion. Meetings and workload were planned around Andrew's preferences and needs, as discussed above. Beth's prior experience of working with patient partners, and the potential challenges of this, may have helped to inform this ongoing negotiation and to pre-empt potential difficulties.

It is important to acknowledge that due to Andrew's professional background, he had some preexisting insight into the university system that not all patient partners have. Developing accessible summary materials for patient partners to cover this would be useful, particularly for those interested in joining a PhD project. These could introduce the long-term nature of the involvement and some of the relevant aspects of 'the dance' which they may benefit from knowing in advance. Formalising the process of formative and summative evaluation of the collaboration can strengthen learning and ensure that future experiences continue to become more positive over time (De Wit et al., 2011).

We also acknowledge that barriers to becoming a patient partner are higher for people whose voices are often not heard in research. We recognise the value of both traditional literacy and digital literacy, particularly in the time of COVID-19, when much more PPI will be conducted virtually. We hope 
this case study provides practical suggestions for working effectively with patient partners throughout the doctoral process, and offers suggestions for formalising the process to support both parties.

\section{Acknowledgements}

We gratefully acknowledge the support of the other members of the supervisory team throughout this process (Dr Emma Dures, Professor Sarah Hewlett and Professor Diana Harcourt). We also thank Dr Emma Dures and Dr Caroline Flurey for their comments on an earlier draft of this paper.

\section{Declarations and conflicts of interest}

\section{Conflicts of interest statement}

The authors declare no conflicts of interest with this work. All efforts to sufficiently anonymise the author during peer review of this article have been made.

\section{References}

Barker, J., Moule, P., Evans, D., Phillips, W. and Leggett, N. (2020) 'Developing a typology of the roles public contributors undertake to establish legitimacy: A longitudinal case study of patient and public involvement in a health network'. BMJ Open, 10 (5), 1-7. https://doi.org/10.1136/bmjopen-2019-033370.

Coupe, N. and Mathieson, A. (2019) 'Patient and public involvement in doctoral research: Impact, resources and recommendations'. Health Expectations, 23 (1), 125-36. https://doi.org/10.1111/hex.12976.

Dawson, S., Ruddock, A., Parmar, V., Morris, R., Cheraghi-Sohi, S., Giles, S. and Campbell, S. (2020) 'Patient and public involvement in doctoral research: Reflections and experiences of the PPI contributors and researcher'. Research Involvement and Engagement, 6 (1), 1-13. https://doi.org/10.1186/s40900-020-00201-w.

De Wit, M. and Adebajo, A. (2019) 'Unique role of rheumatology in establishing collaborative relationships in research: Past, present and future of patient engagement'. Annals of the Rheumatic Diseases, 78 (3), $293-6$. https://doi.org/10.1136/annrheumdis-2018-214387.

De Wit, M.P.T., Berlo, S.E., Aanerud, G.J., Aletaha, D., Bijlsma, J.W., Croucher, L., Da Silva, J.A.P., Glüsing, B., Gossec, L., Hewlett, S., Jongkees, M., Magnusson, D., Scholte-Voshaar, M., Richards, P., Ziegler, C. and Abma, T.A. (2011) 'European League Against Rheumatism recommendations for the inclusion of patient representatives in scientific projects'. Annals of the Rheumatic Diseases, 70 (5), 722-6. https://doi.org/10.1136/ard.2010.135129.

Ennis, L. and Wykes, T. (2013) 'Impact of patient involvement in mental health research: Longitudinal study'. British Journal of Psychiatry, 203 (5), 381-6. https://doi.org/10.1192/bjp.bp.112.119818.

Gilbert, D. (2019) 'Rethinking engagement'. BJPsych Bulletin, 43 (1), 4-7. https://doi.org/10.1192/bjb.2018.55.

Goel, N. (2020) 'Conducting research in psoriatic arthritis: The emerging role of patient research partners'. Rheumatology, 59 (1), i47-55. https://doi.org/10.1093/rheumatology/kez338.

Hewlett, S., De Wit, M., Richards, P., Quest, E., Hughes, R., Heiberg, T. and Kirwan, J. (2006) 'Patients and professionals as research partners: Challenges, practicalities, and benefits'. Arthritis Care and Research, 55 (4), 676-80. https://doi.org/10.1002/art.22091.

Holmes, L., Cresswell, K., Williams, S., Parsons, S., Keane, A., Wilson, C., Islam, S., Joseph, O., Miah, J., Robinson, E. and Starling, B. (2019) 'Innovating public engagement and patient involvement through strategic collaboration and practice'. Research Involvement and Engagement, 5 (1), 1-12. https://doi.org/10.1186/s40900-019-0160-4.

Janamian, T., Crossland, L. and Wells, L. (2016) 'On the road to value co-creation in health care: The role of consumers in defining the destination, planning the journey and sharing the drive'. Medical Journal of Australia, 204 (7), S12-4. https://doi.org/10.5694/mja16.00123.

Jones, B. (2020) Patient Activation in Inflammatory Arthritis. Bristol: UWE Bristol.

NIHR (National Insitute for Health Research) (2021) 'Payment guidance for researchers and professionals'. Accessed 15 July 2020. https://www.invo.org.uk/good-practice-for-payment-and-recognition-things-to-consider/.

Ocloo, J. and Matthews, R. (2016) 'From tokenism to empowerment: Progressing patient and public involvement in healthcare improvement'. BMJ Quality and Safety, 25 (8), 626-32. https://doi.org/10.1136/bmjqs-2015-004839.

Tomlinson, J., Medlinskiene, K., Cheong, V.L., Khan, S. and Fylan, B. (2019) 'Patient and public involvement in designing and conducting doctoral research: The whys and the hows'. Research Involvement and Engagement, 5 (1), 1-12. https://doi.org/10.1186/s40900-019-0155-1. 